\title{
Development of a systematic career coaching program for medical students
}

\author{
Yera Hur ${ }^{1}, \mathrm{~A}$ Ra $\mathrm{Cho}^{2}$ and Mihye Kwon ${ }^{3}$ \\ ${ }^{1}$ Department of Medical Education, Konyang University College of Medicine, Daejeon, ${ }^{2}$ Department of Medical \\ Education, College of Medicine, The Catholic University of Korea, Seoul, and ${ }^{3}$ Department of Internal Rheumatism, \\ Konyang University College of Medicine, Daejeon, Korea
}

Purpose: This study aimed to develop a systematic career-coaching program (SCCP) that can be used by medical teaching schools to address a growing need for career-coaching. The program objectives were to help students (1) develop a comprehensive self-understanding of their aptitudes, interests, and personality traits; (2) explore possible career choices and decide on a career path; and (3) develop the competencies needed to prepare for their future careers.

Methods: The SCCP was based on the ADDIE (analysis, design, development, implementation, and evaluation) model and decision-making questioning model. Medical professionals, medical education and career counseling experts, and students participated in designing the program.

Results: The SCCP describes coaching content, tools, operational methods, and appropriate timing, and identifies the professionals and specialists who can offer their expertise in the different coaching phases. It is designed to allow medical schools to offer the program in segments or in its entirety, depending on the curriculum and environment.

Conclusion: The SCCP represents a viable career-coaching program for medical students that can be applied in part or in its entirety, depending on a medical school's curriculum and educational environment.

Key Words: Career choice, Counseling, Medical students, Mentoring, Professionalism

\section{Introduction}

Korean medical schools have two issues related to career guidance. The first issue is that a significant number of students entering medical schools enroll without a clear occupational goal. This occurs because they have not had time to fully explore possible career paths during their adolescence, and/or because their decision to enter medical school is based on their social and economic status and demands from their surroundings, such as their families $[1-3]$. The second issue relates to the fact that physicians' roles vary socially, and the number of graduates in specializations other than clinical practice is increasing $[4,5]$. This suggests that students are making career decisions not before, but after entering medical school, which further suggests that medical students are learning about career paths other than clinical practice during their medical training.

In this context, the demand for career guidance
Received: October 27, 2017 • Revised: January 15, 2018 • Accepted: January 16, 2018 Corresponding Author: Mihye Kwon (https://orcid.org/0000-0002-1660-1770) Department of Internal Rheumatism, Konyang University College of Medicine, 158 Gwanjeodong-ro, Seo-gu, Daejeon 35365, Korea

Tel: +82.42.600.6766 Fax: +82.42.600.9090 email: mhkwon@kyuh.ac.kr
Korean J Med Educ 2018 Mar; 30(1): 41-50. https://doi.org/10.3946/kjme.2018.80 eISSN: 2005-7288

(C) The Korean Society of Medical Education. All rights reserved. This is an open-access article distributed under the terms of the Creative Commons Attribution Non-Commercial License (http:// creativecommons.org/licenses/by-nc/3.0/), which permits unrestricted non-commercial use, distribution, and reproduction in any medium, provided the original work is properly cited. 
programs is growing. Many studies have emphasized the need for career guidance [6-9]; however, very little research has explored how systematic career-coaching programs (SCCPs) could be designed to help medical students evaluate their career options [10-12]. Instead, medical education negatively impacts medical students' career choices, because they are offered only informal career-coaching, which is buried in the hidden curriculum. Oser et al. [13] indicated that in United States, the influence of professors and senior students who are respectful and interested in their profession greatly compensates for the absence of systematic and professional career counseling in medical education. Therefore, students may pursue informal mentorship for career-related reasons [14].

The situation in Korea is no different. Medical students consult with family members, friends, professors, and senior students when making career decisions [15]. However, by contributing to basic selfunderstanding and awareness of various career opportunities, career-coaching can encourage students to acquire skills that include career planning-including career exploration and design-, selecting a preferred specialty, and preparing to accept a job in that field. Effective career guidance is premised on a step-by-step system and a continuing process [16,17].

Career-coaching also helps students develop the competencies needed for adaptation. This goal is difficult to achieve within the existing curriculum, and we believe that systematic and continuing career guidance is thus needed. Therefore, the objective of this research was to develop a career-coaching program with the following four overarching goals: (1) To help individuals make choices consistent with their personal goals and based on their own self-understanding - of their personalities, occupational values, interests, and aptitudesgleaned through various tests and counseling. (2) To develop a career-coaching program that includes career planning, preparation, selection, and capacity building for adaptation after entering the career path. (3) To develop a systematic mentoring process that operates alongside the influences exerted by a student's family, friends, professors, senior students, and other aspects of the hidden curriculum. (4) To present programs within the structure of the normal academic year to facilitate uninterrupted career-coaching. We used the term coaching instead of mentoring or counseling. Although coaching, counseling and mentoring may use similar skills and approach, the most prominent difference is that coaching is short term task-based and mentoring has longer term relationship. On the other hand, counseling mainly focus on resolving issues of the past and deals with broader issues in depth compared to coaching. Since this study developed a career related program that is yearly based it is more appropriate to use the term coaching rather than mentoring [18].

\section{Methods}

\section{Development of the SCCP}

The SCCP developed in this study was based on the systematic instructional design 'ADDIE' model, which comprises five stages - analysis, design, development, implementation, and evaluation. This framework has been used widely and elaborated by many instructional designers [19]. This study omits the implementation and evaluation stage to suit the purpose of program development. The process of developing an SCCP based on the ADDIE model is shown in Fig. 1.

This study was approved by the Institutional Review Board of Konyang University College of Medicine (IRB no., KYUH 2014-03-014-003). 
Fig. 1. The Process of Developing a Career Coaching Program
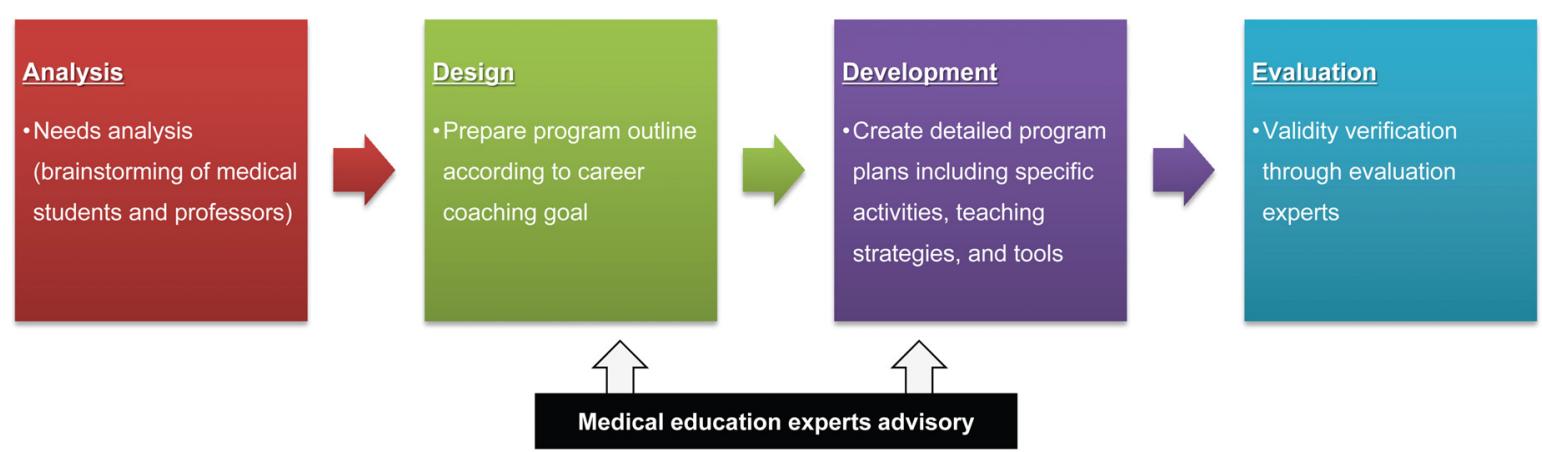

\section{Analysis}

We involved a focus group brainstorming session by two medical education specialists and two medical students. Brainstorming was conducted individually using PubMed. 'Career coaching' and 'career guidance' keywords were used to make reference but personal knowledge and experiences in career coaching were also taken account. The brainstorming contents were relocated to categories based on the reasons of the participants' suggestions through agreement of the researchers. The group analyzed and identified the items that should be included in a career guidance program. The validity of the items derived was confirmed by requiring the consensus of the two researchers to avoid bias or subjective viewpoints and to ensure that all data were considered. The second researcher acted as the auditor of the initial work.

\section{Design}

We were able to design the items derived during the analytical process were arranged according to five career-coaching categories that had been developed in a previous study: career counseling, bridging, educational, field experience, and consulting [20].

\section{Development}

The systematic plans that included detailed course content, teaching strategies, and tools were developed

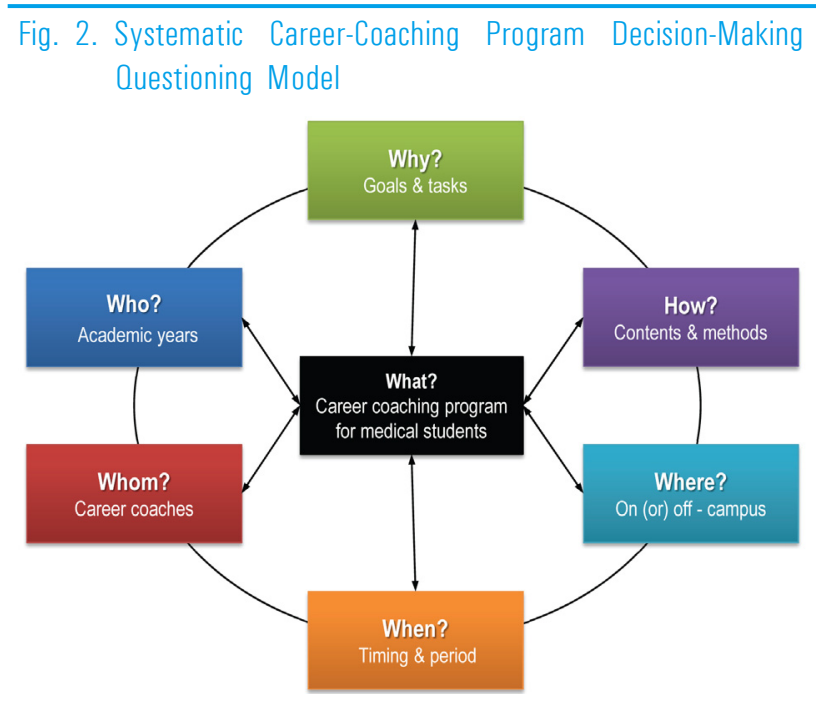

according to the outline. Two medical education experts and two career-counseling experts evaluated the program's validity, and the operational base was classified into two categories-on-campus and off-campus (local community) bases - by experts from various fields.

At design and development stage, we used Yun's decision-making questioning model [21]. The decisionmaking questioning model identifies the problem brought up by the question "what". And when this problem is solved, we determine the competencies needed for the students and then decide the program that needs to be developed and applied. Also, in order to solve the problem, six additional questions are used-whom, who, how, when, and where. Based on the decision-making questioning model, we used six questions as shown in Fig. 2. In addition, the question "why" determined what 
kind of career coaching program is necessary for medical students including goals and tasks. We decided on the content and method of education of the specific program through the question "how", and decided the content of administration method base by the question "where". Finally, after determining the timing and duration of the program with the question "when", we used the question "who" in order to determine the subject of the program.

\section{Results}

\section{Needs assessment of the career-coaching program}

The needs assessment analysis used to develop the
SCCP was based on a career-coaching model developed previously [20]. After using the model to confirm which program items the students required, two students and two professors described the preferred contents of career-coaching programs and verified their agreement with the findings of the two researchers and one auditor who participated in this study (Table 1).

\section{Coaching program}

Based on these findings, we were able to design a career-coaching program that described appropriate educational content, tools, and teaching strategies. To enhance the program's continuity, a career-coaching step was included, for which goals were developed (Fig. 3). A detailed blueprint was then drafted for the SCCP using decision-making model (Fig. 4).

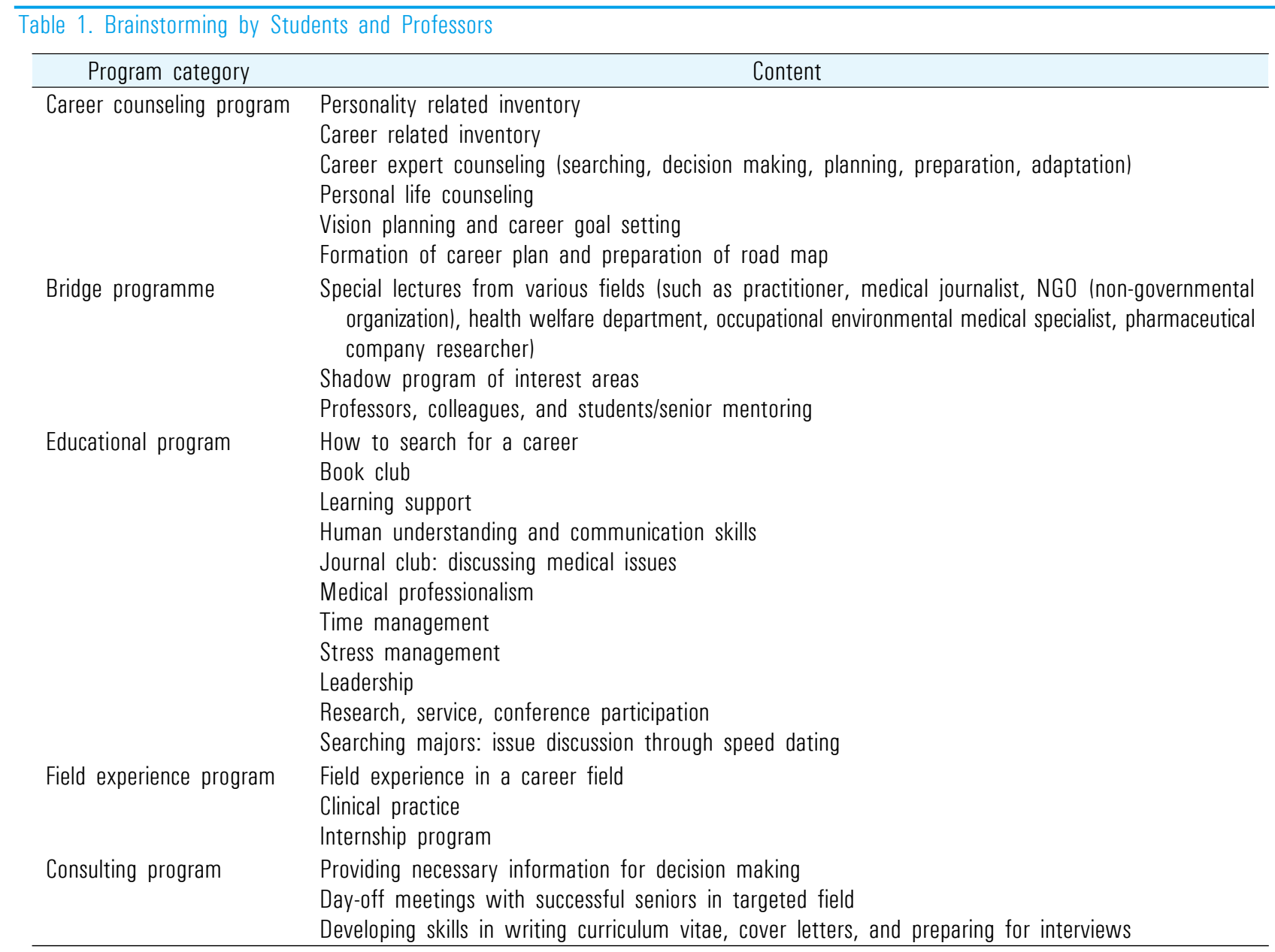


Fig. 3. An Outline of a Career-Coaching Program

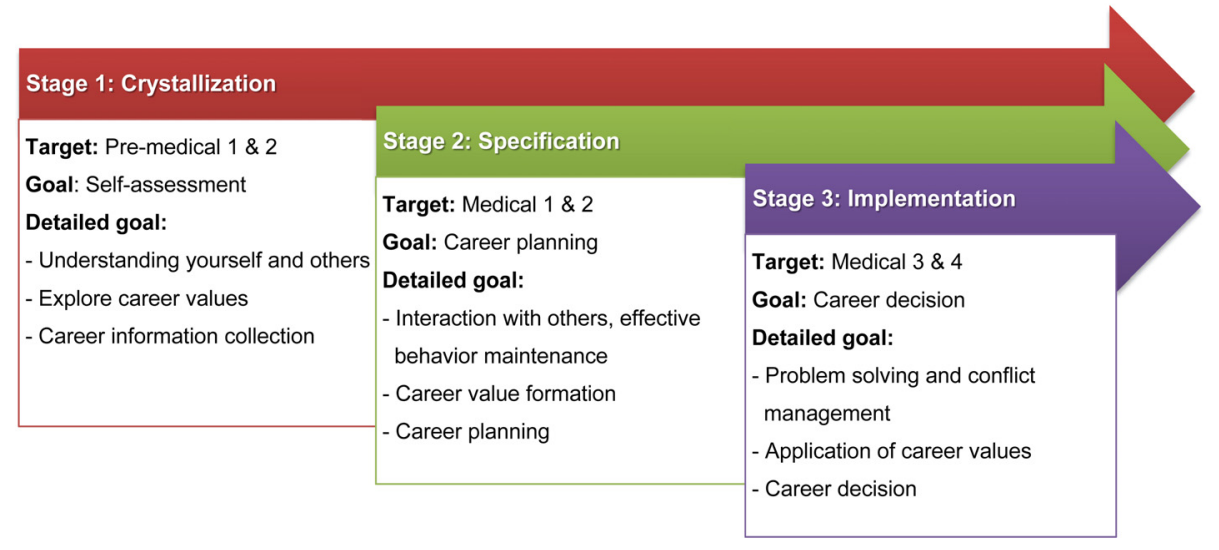

Fig. 4. Systematic Career-Coaching Program by Academic Year

\begin{tabular}{|c|c|c|c|c|c|c|c|c|c|}
\hline \multicolumn{2}{|c|}{ Why } & Whom & \multirow{2}{*}{\multicolumn{3}{|c|}{$\begin{array}{l}\text { How } \\
\text { Program }\end{array}$}} & & \multirow{3}{*}{ Who } & \multirow{3}{*}{ When \& how long } & \multirow{3}{*}{ Where } \\
\hline \multirow{2}{*}{ Goals } & \multirow{2}{*}{ Tasks } & \multirow{2}{*}{$\begin{array}{c}\text { Academic } \\
\text { years }\end{array}$} & & & & Method & & & \\
\hline & & & \multicolumn{3}{|c|}{ Content } & & & & \\
\hline \multirow{4}{*}{$\begin{array}{c}\text { Self- } \\
\text { assessment }\end{array}$} & \multirow{4}{*}{ Crystallization } & \multirow{4}{*}{$\begin{array}{c}\text { Pre- } \\
\text { medical } \\
1 \& 2\end{array}$} & \multirow{3}{*}{ Counseling } & \multicolumn{2}{|c|}{ 1. Career preparation, Job value, STRONG occupational interest inventory } & 目, $\bullet$ & \multirow{3}{*}{ Counselor } & $\begin{array}{c}\text { Beginning of PM first \& } \\
\text { second year }\end{array}$ & On campus \\
\hline & & & & \multicolumn{2}{|c|}{ 2. Geometry Psychological Assessment, MBTI, NEO, stress survey and career search activity } & 目, $\square$ & & $\begin{array}{c}\text { Beginning of PM first \& } \\
\text { second year }\end{array}$ & On campus \\
\hline & & & & \multicolumn{2}{|c|}{ 3. Personal life monitoring, school adaptation, general career distress counseling } & $\bullet$ & & Periodically & On campus \\
\hline & & & \multirow{2}{*}{ Bridge (1) } & \multicolumn{2}{|l|}{ 1. Special Lectures in various fields } & $\mathbf{\square}$ & $\begin{array}{c}\text { Professor \& expert } \\
\text { group }\end{array}$ & PM first year & On/off campus \\
\hline \multicolumn{3}{|c|}{ Competencies } & & \multicolumn{2}{|c|}{ 2. Meeting with a mentor (senior student, professor): study skills, career, personality coaching } & $\diamond$ & Mentor & $\begin{array}{l}\text { PM first \& second year } \\
\text { mentoring }\end{array}$ & On/off campus \\
\hline \multirow{3}{*}{\multicolumn{3}{|c|}{$\begin{array}{l}\text { A: Self-esteem navigation, understanding } \\
\text { others } \\
\text { B: Search for job values, explore information } \\
\text { C: Career planning, understanding the decision } \\
\text { making process }\end{array}$}} & & \multicolumn{2}{|l|}{ 1. Exploring career information } & 曲 & Counselor & Beginning of PM first year & On campus \\
\hline & & & Educational & \multicolumn{2}{|c|}{ 2. Communication skills, learning strategies, stress management } & $\mathbf{\square}, \mathbb{Q}$ & Professor & PM first \& second year & On campus \\
\hline & & & & \multicolumn{2}{|l|}{ 3. Book reading coaching - link with bridge (1-2) } & $\diamond$ & Mentor & $\begin{array}{l}\text { PM first \& second year } \\
\text { mentoring }\end{array}$ & On campus \\
\hline Support & \multicolumn{4}{|c|}{ Student counseling center, Mentoring Center, On/off-line career center, Admission Committee } & \multicolumn{4}{|c|}{ Motivation, mentoring, medical humanities curriculum } & Connection \\
\hline \multirow{4}{*}{$\begin{array}{l}\text { Career } \\
\text { planning }\end{array}$} & \multirow{4}{*}{ Specification } & \multirow{4}{*}{$\begin{array}{c}\text { Medical } \\
1 \& 2\end{array}$} & & 1. Career preference, vocational aptitude test & & 目 $\bullet$ & & Beginning of first year & On campus \\
\hline & & & Counseling & $\begin{array}{l}\text { 2. LEP leadership inventory, FIRO-B interpersor } \\
\text { evaluation test and career search activity }\end{array}$ & racteristics, K-BASC-2 emotion-behavior & 目, $\square$ & Counselor & $\begin{array}{l}\text { Beginning of first \& } \\
\text { second year }\end{array}$ & On campus \\
\hline & & & & $\begin{array}{l}\text { 3. Career roadmap preparation, career plan refir } \\
\text { monitoring }\end{array}$ & t coaching, career planning implementation & $\bullet$ & & Periodically & On campus \\
\hline & & & & 1. Specialty interest groups - shadow program & & 目, $\square$ & $\begin{array}{l}\text { Professor \& expert } \\
\text { group }\end{array}$ & First year & On/off campus \\
\hline & Competencies & & Bridge (2) & $\begin{array}{l}\text { 2. Meeting with a mentor (senior, professor)-con } \\
\text { conferences }\end{array}$ & y service, research skills, attending & $\diamond$ & Mentor & $\begin{array}{l}\text { First \& second year } \\
\text { mentoring }\end{array}$ & On/off campus \\
\hline A: Intensifying & elf-esteem, interac & ion with & & 1. Career planning and decision-making & & 㖆 & Counselor & Beginning of first year & On campus \\
\hline $\begin{array}{l}\text { others } \\
\text { B: Formation of } \\
\text { information }\end{array}$ & job values, interpre & ting career & Educational & 2. Medical professionalism, medical communica & ills, time management, leadership skills & $\mathbf{\square}, \square$ & Professor & First \& second year & On campus \\
\hline C: Career plan & ing, implementatio & & & 3. Searching majors - issue discussion through & dating & $\mathbf{\square} \bullet$ & $\begin{array}{l}\text { Professor \& expert } \\
\text { group }\end{array}$ & Second year & On campus \\
\hline Support & & tudent couns & eling center, Mento & ring Center, on/off-line career center & Leadership, professionalism, medical hum & inities, elective & ourses, research capac & acity building curriculum & Connection \\
\hline & & & & 1. Job readiness test & & 目, $\bullet$ & Counselor & Beginning of third year & On campus \\
\hline $\begin{array}{l}\text { Career } \\
\text { decision }\end{array}$ & $\begin{array}{l}\text { Implementation } \\
\text { \& stabilization }\end{array}$ & $\begin{array}{l}\text { Medical } \\
3 \& 4\end{array}$ & Counseling & 2. Counseling: personal life, employment, proble & ing, conflict management & $\bullet$ & Counselor & Periodically & On campus \\
\hline & & & & 1. Residency preparation, planning clerkship & & 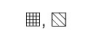 & Professor & Third year & On campus \\
\hline & Competencies & & Fieta Expentilue & 2. On \& off campus internship and clinical intern & inked with regular courses & 目, $\square$ & Professor & Fourth year & On/off campus \\
\hline $\begin{array}{l}\text { A: Maintaining } \\
\text { effective behav }\end{array}$ & $\begin{array}{l}\text { elf-esteem, mainta } \\
\text { ors }\end{array}$ & & & 1. Gathering job information and making rationa & & 曲 & Consultant & Beginning of third year & On campus \\
\hline $\begin{array}{l}\text { B: Application o } \\
\text { information }\end{array}$ & f values, utilization & f career & Consulting & 2. Providing career information and resources & & $\diamond$ & Consultant & Regular & On campus \\
\hline $\begin{array}{l}\text { C: Career path } \\
\text { strategies step }\end{array}$ & $\begin{array}{l}\text { decision making, e } \\
\text { ing into career patt }\end{array}$ & tablishing & & 3. Day-off meeting with seniors in targeted field: & llum vitae, self introduction, mock interview & 目, $\square, \bullet$ & $\begin{array}{l}\text { Professor \& expert } \\
\text { group }\end{array}$ & Periodically & On campus \\
\hline Support & Student cour & seling center, & Mentoring Center, & On/off-line career center, Graduates Committee & Vision experience cou & e, electives, st & dent intern training cours & urse & Connection \\
\hline
\end{tabular}

A: Understanding oneself, B: Understanding the occupation and career world, exploring a career, C: Career design and preparation, MBTI; Myer-Briggs Type Indicator, NEO II: Neuroticism extraversion openness to experience II, LEP: Leading Edge Portrait, FIRO-B: Fundamental Interpersonal Relations Orientation-Behavior, K-BASC-2: Korea-Behavior Assessment System for Children second edition, 目: Individual, $\mathbf{\square}$ : Large lecture, $\square$ : Small group

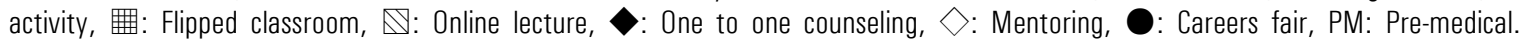


The SCCP describes specific program content, timing, operating methods, and what specializations the career coaches should have, so that medical schools can offer the program in segments or in its entirety, depending on their curriculum and environment. The program was divided into three continuing stages: self-assessment, career planning, and career path decision-making. The counseling program is offered in all academic years, but different content is offered as students move through the various stages of career-coaching. This program has been assigned to a professional counselor within the campus and is programed mainly as individual activities, roundtable counseling, or small group activities. Participating in this program will deepen students' selfunderstanding, enable them to conduct systematic searches of possible careers, and prepare them to make decisions regarding their career paths. For example, in the first two years during their premedical studies, students gather information to help them prepare for their careers, complete job value tests to develop career searching behavioral skills, and identify values that are important in choosing a career while pursuing their goals. In the first two years of medical school, their job preferences are determined and they complete vocational aptitude tests to obtain information on the career that suits their interests, personalities, lifestyles, aptitudes, and competencies as well as their abilities to succeed in that field. In medical years 3 and 4, they complete a job preparation test to obtain information pertinent to their actual employment, such as their job motivations, job search skills, abilities to gather employment information, and interpersonal skills.

The bridge program is conducted in pre-medical years 1 and 2 (PM1, 2) and medical years 1 and 2 (M1, 2) levels, where PM1 students have access to the professor, an expert group, as well as a mentor. In addition, the bridge program allows students to explore their options from a wider perspective by attending special lectures in various career fields in pre-medical years 1 and 2 and in medical years 1 and 2. After completing these steps, students in medical years 1 and 2 will confirm their areas of interest; they will also have acquired in-depth experience in specific areas through specialty interest group shadow programs. In particular, the bridge program has been linked with mentoring that provides coaching on study skills, careers, and personality types, as well as coaching related to volunteer services, research, and conference attendance.

All bridge programs have extended off campus and are not limited to within the campus; this is so that anyone can get practical information on various courses. The educational program is also conducted for the PM1, PM2, and M1 grades, just like the 'bridged' program. In PM1 and PM2, career education is conducted to enable 'career search'. Therefore, a professional counselor is responsible for the program. The flipped learning approach was selected as the education strategy: the method of searching for career information is learned online, while the actual career information search is conducted within the classroom. This kind of career education becomes more concrete in career decision-making and planning at the M1 and M2 levels. Considering that it is possible to secure more time for career guidance during the M1 and M2 levels, as compared to the M3 and M4 levels, the basic skills necessary for starting a career and maintaining it were included, for example, communication, learning strategy, stress management, leadership, and time management. Since students choose their career paths in their third and fourth years of medical school, we ended the bridge and educational program and instead offered field experience and a consulting program at the M3 and M4 levels to help them enter and adapt to the career path they had selected. The field experience program was designed to be administered by 
a professor and includes two core contents: an internship and a link to clinical clerkships. The consulting program helped students not only to plan, prepare, and select their career paths themselves, but also develop the competencies required for embarking on that path and making adjustments to their path when necessary after graduation. The program is conducted by a consultant, and an online program is also available for any corrections that need to be made. In particular, we tailored program development to not only help students themselves plan, prepare, and select a career path but also to help develop their competencies required to enter that profession after graduation and make adjustments when needed.

\section{Discussion}

Medical students need a systematic, continuous approach to career-coaching, with tailored content that meets their specific needs at their academic level. In reality, however, career-coaching has been limited to the provision of a perfunctory counseling program at a student counseling center, and usually involves one-off counseling. Consequently, there are few programs that can actually help students develop their career paths [3,12,22]. Given this background, rather than being offered one-off counseling or a perfunctory team counseling session, to be successful in their desired careers, medical students must have access to systematic career-coaching that gives them the opportunity to explore various career paths based on accurate information; acknowledges their personalities, strengths, and weaknesses; and teaches them to make rational decisions regarding their careers.

Based on the model of Hur [20] and the decisionmaking questioning model of Yun et al. [21], we developed a career-coaching map for medical students for each item and academic year as per ADDIE model. This map will foster development of the competencies needed to execute the required tasks at each stage of career-coaching. It has been reported that a systematic career guidance program, career counseling resources, and mentoring have had more positive effects on career choices than the traditional faculty advisor system [23-28]. Therefore, we developed the SCCP which reflects the needs of medical students and faculties - for medical schools. With regard to the duration, the segments of the program may last one semester or throughout the academic year, or could be regulated individually, depending on the educational environment of the institution. For example, the counseling sessions in PM1 are mostly based on personal assessment and inventories, which may require one to three counseling sessions with the counselor. The mentoring sessions in M1 and M2, however, will be required to be longer sessions because the students will need to cover research experiences and community service. Such sessions may last either for one semester or for the whole year.

The SCCP has the following specific characteristics. First, career-coaching is divided into three stages, the programs required for each period are decided, and detailed content is structured systematically to ensure that it is appropriate to the students' academic level and that it is offered continuously, according to the goals of career-coaching. The second characteristic of the SCCP is that it includes not only career-coaching, but also specific educational programs that teach communication skills, stress management, time management, leadership skills, and skills needed to build medical professionalism. This characteristic addresses the observation that the purpose of career-coaching is not only to help students plan, prepare, and select a career path, but also to develop the competencies required to enable them to 
be successful in their chosen career after graduation, including being able to adapt as needed. The SCCP's third characteristic is its provision of information on how best to manage the program; how, when, and where to deliver the program's sub-topics and content; and who can be responsible for its operation. Taken all together, the SCCP is a model that should be adapted by schools and individuals at the institutional level to suit their unique educational environments. More specific content and educational materials such as tailored programs, handouts, and guidebooks should be developed with regard to students' educational goals and outcomes. Especially, selecting professors, counselors, consultants, and mentors for the SCCP may not be easy. Depending on the educational and financial support of the institution, some experts could be selected from outside the institution. However, for continuity and quality assurance, it would be best if most of the mentors and professors were recruited from within the institution in one condition; they should have a clear understanding of the objectives of their particular program and should possess the professional skills needed to conduct specific sessions. To ensure this, faculty development programs, such as mentoring training programs, may be necessary, for example, five to six mentoring workshops for the professors during the summer vacation to provide specific training to enhance their mentoring skills. The selection process and criteria for the selection of staff may differ according to different programs, but the criteria should closely match accessibility, ability, and desire. This means that one should be accessible to (that is, easy to meet with) the students when needed; should have the capability of fulfilling the responsibilities of such a position, with adequate experience in the field; and should have the passion and desire to be involved in the program. Also, consideration should be given to selecting peer mentors rather than senior professors, which may provide students easier access $[29,30]$.

Since career-coaching items were derived from a literature search and brainstorming of a focus group, efforts to represent the needs of both career-coaching subjects and beneficiaries were limited. In addition, this research did not proceed to the implementation and evaluation stages of the developed career-coaching program. However, because medical schools have proposed concrete ideas for each item and stage, based on their career-coaching goals, the SCCP provides practical materials and guidance that will enable the schools to apply the suggested program in segments or in its entirety, depending on the specifics of their educational environments. We will investigate the effectiveness of the SCCP further using a pilot study, and, based on these complementary studies, we will be able to finalize the SCCP in the near future. Specifically, we will apply PM1, PM2, M1, and M2 to the career guidance mentoring class, which can be added to the medical curriculum; to verify the effectiveness of this program, the pre-test and post-test will be compared. We would also like to suggest the following for future research. First, research is required to assess and evaluate necessary resources such as cost, infrastructure, and cooperative networks in the execution of the career-coaching program. The result of this study should then be carefully analyzed; this analysis will act as valuable feedback that can be implemented into the introduction and operation stages of the SCCP. Second, the importance of and necessity to develop faculty development programs for members of the faculty or mentors of the SCCP should also be looked into. Third, if the SCCP is to be executed at the individual medical school level, it will be necessary to develop specific educational materials (or guidelines) that are appropriately tailored to the educational environment of specific institutions. We hope that these steps will lead to more extensive research on this topic. 
BMC Med Educ. 2013;13:81.

6. Deiorio N, Juve AM. Developing an academic coaching program. MedEdPublish. 2016;5(3):57.

7. Kassim SS, McGowan Y, McGee H, Whitford DL. Prepared to practice?: perception of career preparation and guidance of recent medical graduates at two campuses of a transnational medical school: a crosssectional study. BMC Med Educ. 2016;16:56.

8. Sandars J, Patel R, Steele H, McAreavey M; Association for Medical Education Europe. Developmental student support in undergraduate medical education: AMEE guide no. 92. Med Teach. 2014;36(12):1015-1026.

9. Yager J, Bagga MS, Hilty DM. Fostering a positive early-career academic environment. In: Roberts LW, Hilty DM, eds. Handbook of Career Development in Academic Psychiatry and Behavioral Sciences. Arlington, USA: American Psychiatric Association Publishing; 2017:385-394.

10. Bittaye M, Odukogbe AT, Nyan O, Jallow B, Omigbodun AO. Medical students' choices of specialty in The Gambia: the need for career counseling. BMC Med Educ. 2012;12:72.

11. Mehmood SI, Norcini JJ, Borleffs JC. Newly qualified doctors' views on the significance and accessibility of career advice during medical training in Saudi Arabia. Med Teach. 2013;35 Suppl 1:S20-S24.

12. Yoo HH, Park KH, Kim SY, Im SJ. The effectiveness of a career design program for medical students. Korean Med Educ Rev. 2015;17(3):131-139.

13. Oser TK, Haidet P, Lewis PR, Mauger DT, Gingrich DL, Leong SL. Frequency and negative impact of medical student mistreatment based on specialty choice: a longitudinal study. Acad Med. 2014;89(5):755-761.

14. Park JJ, Adamiak P, Jenkins D, Myhre D. The medical students' perspective of faculty and informal mentors: a questionnaire study. BMC Med Educ. 2016;16:4.

15. Lee JH, Kim GI, Park KH, Yune SJ. Differences in factors 
affecting medical specialty choices between medical college students and graduate medical school students. Korean J Med Educ. 2009;21(4):393-402.

16. Lim U, Kim AK. Career guidance and transition to labor market. Sejong, Korea: Korea Research Institute for Vocational Education and Training; 2006.

17. National Career Development Association. National career development guidelines (NCDG) framework. http://www.ncda.org/aws/NCDA/asset_manager/get_file/3 384?ver=2825051.2017. Published 2017. Accessed April $27,2017$.

18. Passmore J. Coaching and mentoring: the role of experience and sector knowledge. Int J Evid Based Coach Mentor. 2007;5(Special Issue 1):10-16.

19. Molenda M. In search of the elusive ADDIE model. Perform Improv. 2003;42(5):34-37.

20. Hur Y. Development of a career coaching model for medical students. Korean J Med Educ. 2016;28(1): 127-136.

21. Yun CY, Yune SJ, Kim JS. The effects of school based learning consultation with expert model on learning strategies. Korean J Educ Psychol. 201 1;25(25):545-567.

22. Chung EK. The career counselling program in medical schools outside Korea. Korean Med Educ Rev. 2013; 15(2):82-86.

23. Sastre EA, Burke EE, Silverstein E, et al. Improvements in medical school wellness and career counseling: a comparison of one-on-one advising to an Advisory
College Program. Med Teach. 2010;32(10):e429-e435.

24. Harris JA, McKay DW. Evaluation of medical career-counseling resources across Canada. Teach Learn Med. 2012;24(1):29-35.

25. Deutsch T, Honigschmid P, Frese T, Sandholzer H. Early community-based family practice elective positively influences medical students' career considerations: a pre-post-comparison. BMC Fam Pract. 2013;14:24.

26. Welbergen L, Pinilla S, Pander T, et al. The Facharzt Duell: innovative career counselling in medicine. GMS Z Med Ausbild. 2014;31(2):Docl7.

27. Waddell J, Spalding K, Navarro J, Gaitana G. Integrating a career planning and development program into the baccalaureate nursing curriculum: part III. Impact on faculty's career satisfaction and confidence in providing student career coaching. Int J Nurs Educ Scholarsh. 2015;12:183-190.

28. Stamm M, Buddeberg-Fischer B. The impact of mentoring during postgraduate training on doctors' career success. Med Educ. 2011;45(5):488-496.

29. Singh S, Singh N, Dhaliwal U. Near-peer mentoring to complement faculty mentoring of first-year medical students in India. J Educ Eval Health Prof. 2014;11:12.

30. Chester A, Burton LJ, Xenos S, Elgar K. Peer mentoring: supporting successful transition for first year undergraduate psychology students. Aust J Psychol. 2013; $65(1): 30-37$. 